\title{
Bowel management for the treatment of pediatric fecal incontinence
}

\author{
Andrea Bischoff $\cdot$ Marc A. Levitt · Alberto Peña
}

Accepted: 29 September 2009/Published online: 15 October 2009

(C) The Author(s) 2009. This article is published with open access at Springerlink.com

\begin{abstract}
Fecal incontinence is a devastating underestimated problem, affecting a large number of individuals all over the world. Most of the available literature relates to the management of adults. The treatments proposed are not uniformly successful and have little application in the pediatric population. This paper presents the experience of 30 years, implementing a bowel management program, for the treatment of fecal incontinence in over 700 pediatric patients, with a success rate of $95 \%$. The main characteristics of the program include the identification of the characteristics of the colon of each patient; finding the specific type of enema that will clean that colon and the radiological monitoring of the process.
\end{abstract}

Keywords Fecal incontinence - Bowel management · Enemas $\cdot$ Anorectal malformations

\section{Introduction}

Fecal incontinence is an incapacitating, devastating problem that affects children and adults all over the world. The problem seems to be underestimated, most likely partly because it is not easy for affected adults or parents of children to talk about a subject that has been a taboo through generations.

It is estimated that there are about 135 million births per year in the world $[1,2]$. If we only focus on the two most frequent causes of fecal incontinence in children that are

\footnotetext{
A. Bischoff · M. A. Levitt · A. Peña (凹)

Colorectal Center for Children,

Cincinnati Children's Hospital Medical Center,

3333 Burnet Avenue, ML 2023, Cincinnati, OH 45229, USA

e-mail: alberto.pena@cchmc.org
}

spina bifida and anorectal malformations (ARM) with bad functional prognosis, we can have an estimate of the dimension of the problem. Spina bifida occurs in about one to two out of every 1,000 births [3] and ARM occur in 1 in every 4,000 or 5,000 births [4]. In the authors' series, $25 \%$ of all patients with ARM, regardless of the quality of the treatment that they receive, suffer from fecal incontinence due to the fact that they were born with a very poor functional prognosis type of defects (abnormal sacrum and abnormalities in the cord) [4]. Based on the world statistics, every year approximately 200,000 babies with spina bifida and bowel dysfunction are born; and 8,500 newborns with anorectal malformation and fecal incontinence. In the United States, with better prenatal care, the incidence of spina bifida is $0.46 / 1,000$ births [5], this would represent approximately 2,000 newborns with spina bifida and suffering from bowel dysfunction per year and 265 newborns with anorectal malformation suffering from fecal incontinence. The estimated average life expectancy in the United States is currently 78 years, and worldwide it is 67 years [2]. It is very difficult to estimate the number of patients born with spina bifida and anorectal malformation that are alive and suffering from fecal incontinence. Assuming that the life expectancy for patients with anorectal malformation is 67 years [6]; roughly it is possible that in the USA there are 17,755 patients with bad functional prognosis type of anorectal malformation suffering with fecal incontinence; and using the same rationale, worldwide there would be greater than 500,000 of such patients. In the spina bifida population, there must be many more patients; however, it is harder to estimate numbers, since prenatal diagnosis and postnatal care influence the statistic as well as the level and type of defect $[7,8]$.

Unfortunately, it seems like the health organizations, governments and private institutions have not dedicated 
much in the way of resources to investigations geared trying to find better ways to treat fecal incontinence. As a consequence, most of the patients who suffer from fecal incontinence feel abandoned.

Our experience is mainly in the pediatric population. We have treated a few adults that were born with congenital malformations and came to us looking for help. We found that most of the available literature relates to the management of adults with fecal incontinence [9-37]. Very few papers were specifically related to the pediatric population [13, 38-49]. Fecal incontinence in adults has different etiologies and the type of treatments proposed for adults have little application in children.

In addition to spina bifida and ARM, we have seen many other patients who suffer from fecal incontinence for other reasons that include patients operated on for Hirschsprung's disease [49], sacral agenesis [50, 51], sequelae post trauma and tumors $[52,53]$.

Doctors, nurses, rehabilitation technicians, nutritionists and health-care providers in general have tried different treatments trying to improve the problem of fecal incontinence, most of the time unsuccessfully.

\section{Diet}

Changes in diet have been recommended for many years on a purely empirical basis. Recommendations included laxative food, constipating food, high-fiber diet and increased water intake [14, 16, 18, 27, 46].

It is easy to understand that if an extremely constipating diet is prescribed to a patient with incontinence, he/she, the doctor and the nurse may get the impression of improvement, simply because the patient stops passing stool. That, however, will eventually produce more serious consequences without alleviating the real problem. Occasionally, a bulking forming diet may improve a patient with borderline fecal incontinence because it is more likely for him/ her to feel a formed stool than a liquid one.

All these dietary changes we have seen prescribed in a rather indiscriminate manner with variable, rather poor results. In addition, a concept that is usually missed when diet is prescribed as an adjuvant therapy or main therapy is the need to individualize the treatment. For example, in our experience, a constipating diet is extremely important in patients with fecal incontinence and tendency to diarrhea (hypermotile colon). They are the ones that benefit having a constipating diet, as it will be explained later.

\section{Fiber}

There are two types of fibers: soluble (psyllium, gum, arabic and pectin) that binds water and forms a gel-like substance with it, and insoluble (methyl cellulose, calcium polycarbophil, lignins and hemicelluloses) that does not absorb or dissolve in water, but has a high capacity to bind with bile acid [54]. Soluble fibers tend to bulk the stool, whereas the insoluble fibers tend to make the stool looser.

Fibers have being used, again in an indiscriminate way to try to alleviate the symptoms of fecally incontinent patients [33]. It is understandable that some patients may experience some mild improvement by taking these kinds of medications because some of these fibers, particularly pectin, have the capacity to act like a bulking agent. Patients with borderline fecal control are capable of feeling better a bulky stool rather than liquid stool and that may explain why some authors may claim good results with this kind of treatment alone.

Unfortunately, some of the fibers sold and commercially available also have a laxative effect in addition to the bulking effect. We have found that pectin seems to have a better bulking effect without the laxative component and that is why, when indicated, we like to prescribe it.

In children, the clinician must be alert to the potential negative effect of reduced absorption of vitamins, proteins and energy that fibers can cause [55].

\section{Medication}

Anti-motility agents (anti-diarrheal)

In general, through the years, doctors prescribe medications to decrease the colonic peristalsis as a simple, frequently unsuccessful attempt to treat fecal incontinence. As expected, these drugs may produce an immediate, but temporary relief of the fecal incontinence giving a false good result. The patient may stop passing stool. However, they keep producing stool, and if this is not completely eliminated, accumulation and impaction will occur and eventually the fecal incontinence will be even worse. The most commonly used medication is loperamide since it has a very significant constipating effect. It also increases the tone of anorectal smooth muscle [9], and has less potential for central nervous system and anticholinergic effects as compared to diphenoxylate and difenoxin [27, 30].

Amitriptyline has also been reported as having a positive effect on fecal incontinence due to its anticholinergic effects [30, 32]. Yet, the problem will be the same as the one described for loperamide.

Cholestyramine forms insoluble complexes with bile acids and therefore decreases the amount of water in the stool, decreasing stool frequency and provoking a sense of improvement in patients with fecal incontinence and tendency to diarrhea [37]. When prescribed, vitamin supplementation is advised as its absorption will be impaired. 
Silicates (hydrated aluminum silicate and magnesium aluminum disilicate) bind with water and may produce a constipating effect [27] that may improve the symptoms of a patient with fecal incontinence but will not do anything significant for bowel control.

Bismuth agents have an antisecretory and anti-inflammatory effect [27], so when patients with fecal incontinence suffer from diarrhea, this kind of compound may give the impression of improving the fecal incontinence and tendency to diarrhea but it is actually a constipating agent.

Pro-motility agents (laxative effect)

Medications with a laxative effect such as cisapride, stool softners, laxatives in general, bethanechol and erythromycin may give the impression of improving the symptoms in patients who suffer from hypomotility in addition to fecal incontinence. Actually, as will be discussed later, laxatives have a precise indication in a smaller group of patients that behave like being fecally incontinent, but in reality they suffer from overflow pseudoincontinence, due to chronic fecal impaction. In patients suffering from real fecal incontinence, laxatives have no indication. Unfortunately laxatives do not have a controlled effect, which means that a single dose may produce many unexpected bowel movements, at unpredictable times, which will actually worsen the problem of fecal incontinence.

\section{Biofeedback}

Rehabilitation experts are enthusiastic about the use of biofeedback, but unfortunately the clinical results are rather poor. Patients might experience an improvement in contracting their sphincters, which is manometrically detected, but, in general, this small improvement does not correlate with a better bowel control [20, 29, 56, 57].

\section{Anal plugs}

Anal plugs [58] have been used in children with anorectal malformation and spina bifida and the results when used in combination with a bowel management program were still not good, since only $37 \%$ were successful [44].

\section{Surgery}

Multiple types of operations have been attempted to treat the problem of fecal incontinence [59-72]. In general, we, surgeons dealing with the problem of fecal incontinence have focused on the sphincter (reconstruction, muscle transfer or replacement). No efforts have been made to improve the other two very important elements, indispensable to have bowel control, which is sensation and rectosigmoid motility that explains why the results of all those operations have been less than good. These attempts include the following.

\section{Artificial sphincters}

The reported success rate in the use of artificial sphincters varies from 20 to $60 \%$, but unfortunately complication rates are also very high, from 50 to $60 \%$ [16, 24, 32, 36, $72]$.

\section{Muscle transfer procedures}

Gracilis muscle and gluteus muscle have also been used in an attempt to create voluntary sphincters, with success rates from 35 to $85 \%$ [31, 36]. Lately, with the addition of a nerve stimulator to maintain the muscle tone, some authors are very enthusiastic about improving those results. This experience has been mainly in adults $[31,36]$.

The problem with artificial sphincters and muscle transfer procedures is that they do not improve sensation or rectosigmoid motility, which are the other two equally important and indispensable elements of bowel control. As a consequence, patients that suffer from fecal incontinence and hypomotility would "relax the sphincter or open" the artificial sphincter which will allow the passing of stool. However, due to the poor peristalsis, there may be no bowel movement. Those patients may then need an enema to evacuate their colon. As will be seen later, an enema may be enough to keep a patient clean, without the potential morbidity of these operations In addition, these operations may actually exacerbate the problem of constipation when present [72].

Sphincteroplasties

Different types of sphincter repairs have been attempted with authors claiming success rates varying from 25 to $83 \%$ [31]. It is important to remember that most of these repairs are offered to patients who had sphincter lesions (obstetric trauma) and this is not the case of pediatric patients with congenital problems. Very few publications advocate sphincteroplasties (levatorplasties) in children.

\section{Colostomies}

These procedures are indicated when all modalities of treatment, including surgery, have failed. In our experience, colostomy is rarely indicated, because a patient with 
a normal colon length is capable of forming solid stool and, therefore, is a good candidate to receive our bowel management program, which gives the patients a better quality of life compared with a permanent colostomy.

\section{Electrical stimulation}

Radiofrequency energy delivery to the anal canal

This treatment is based on the concept that collagen deposition and subsequent scarring may increase one's ability to recognize and retain stool improving continence. The results show improvement in scores, but patients are still not clean with this treatment [73-76].

Sacral nerve stimulation

Sacral nerve stimulation has been used with a reported success rate varying between 47 and 90\% [31, 34, 77-79]. This experience has been mainly in adults with one report in children with urological dysfunction and constipation and only $16 \%$ of the patients had complete symptom resolution [80].

Even when this method of management has been reported with good results, the problem in the pediatric population is that most patients do not have the normal nerve pathways or sphincter mechanism. Anorectal malformation patients are born with a spectrum of nerve and muscle deficiencies. Therefore, the nerve stimulation may not give the best good results as have been reported in adults.

\section{Enemas}

Enemas seem to be as old as human beings and they have been used mainly for social, religious, erotic and medical reasons without scientific basis, and lately, also have been used for the treatment of fecal incontinence [38, 47, 48].

The results obtained with the use of enemas for the treatment of fecal incontinence varies with a success rate that goes from 38 to $93 \%$ [81-83].

\section{The authors' bowel management program}

Through the last 30 years, motivated by many children suffering from fecal incontinence, the authors developed, by trial and error, a methodology for the management of fecal incontinence in pediatric patients.

The authors' institution is an international referral center for the treatment of colorectal problems in children. The files of the center include information related to 2,400 patients operated by the authors, since 10 August 1980, until the date of publication. Around $75 \%$ of the entire group has voluntary bowel movements and, therefore, they do not need bowel management. Approximately, 25\% of all these patients with ARM suffer from fecal incontinence [4], and many ARM patients operated at other institutions are also referred to us suffering from fecal incontinence. In addition, we also receive patients operated on for Hirschsprung' disease as well as patients, with spina bifida suffering from fecal incontinence.

The authors consider a moral obligation the management and long-term follow-up of patients that receive an operation. This includes treatment for those that suffer from fecal incontinence. In general, there has been a tendency to abandon these patients. Surgeons like to operate and are not prone to implement medical managements. Pediatricians and gastroenterologists, on the other hand, do not have much experience in the management of these problems. We use the term bowel management for the treatment of fecal incontinence to refer to a program implemented at our institution designed to keep fecally incontinent patients artificially clean in the underwear. The management consists of the administration of a daily individually designed enema, which allows the patient to remain completely clean in the underwear for $24 \mathrm{~h}$ between enemas. In a number of cases, the program includes the medical manipulation of the colonic motility with specific type of diet and/or medications such as loperamide. Thus, the therapeutic elements used by the authors (enemas, diet and medication) are not different than those already mentioned in the literature review. However, what we consider unique characteristics of the bowel management implemented at our institution include the following key components:

A. The use of an individualized type of enema, specifically designed for the size and type of motility of the patient's colon.

B. Radiologic monitoring of the amount and distribution of the stool in the colon as a result of the enema administration that helps us modify the type of enema accordingly.

C. Understanding the difference between true fecal incontinence and pseudoincontinence.

D. Classifying the patient with fecal incontinence into two large groups:

1. those that have a very large colon (hypomotility) (Fig. 1);

2. those that have a rather hyperactive colon and tendency to diarrhea (hypermotility) (Fig. 2).

The management of these two groups of patients (hypomotility and hypermotility) is completely different. 


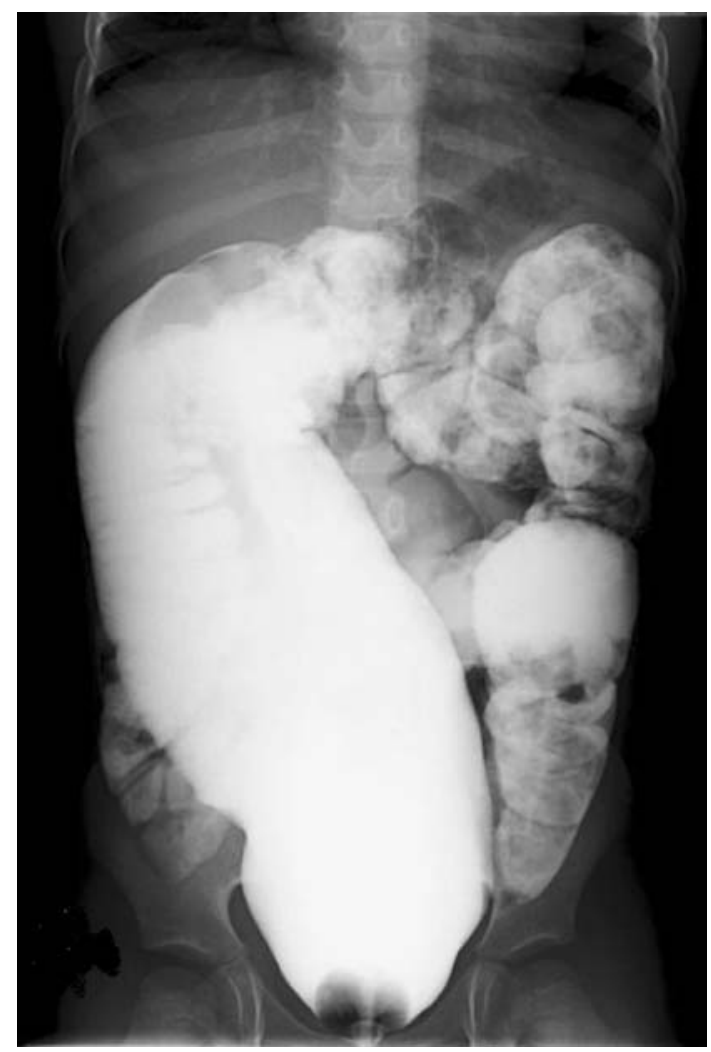

Fig. 1 Contrast enema showing a dilated rectosigmoid

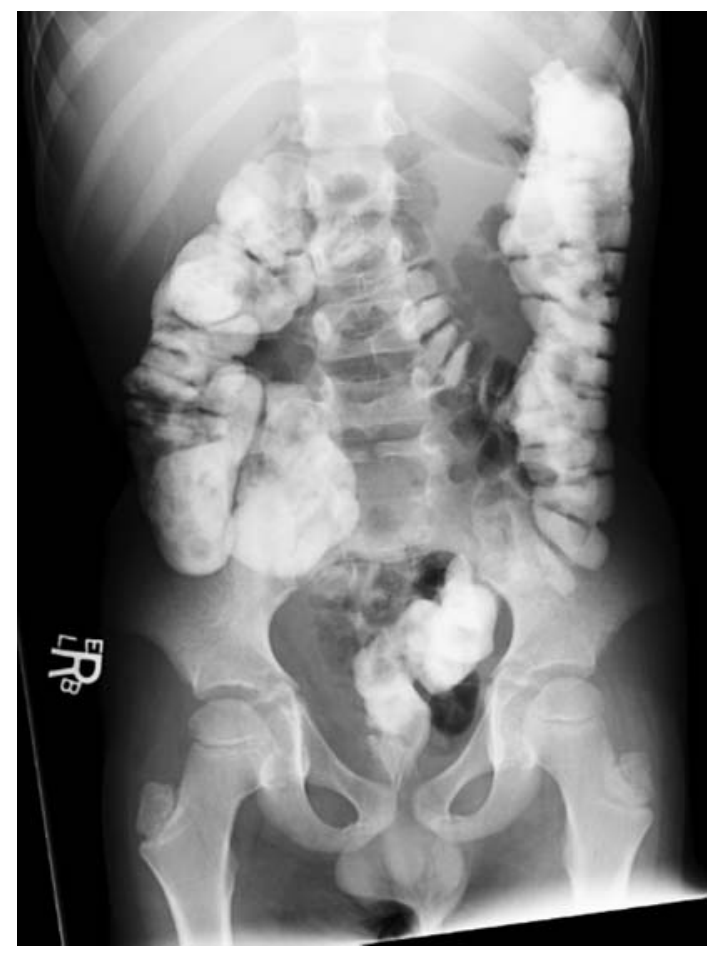

Fig. 2 Contrast enema showing a non-dilated colon
This differentiation is extremely important for the bowel management to be successful.

Most of the authors who currently use enemas for the treatment of fecal incontinence recommend a specific volume or formula for different types of patients [81]. Some authors try to individualize the treatment, but let the parents take the responsibility to do it at home, over a period of weeks or months [83].

In our institution, every month, one entire week is dedicated to the bowel management of a group of usually around 20 patients. The management is done on ambulatory basis. The parents and the patients come every day from Friday to Friday, have an abdominal X-ray film to monitor the amount and distribution of the stool in the colon and have an interview with our nurse to tell her what has been the result of the management. Daily, nurses and physicians meet in a conference room, look at all and each one of the X-ray films of the patients and hear the report of the parents given to the nurses. Based on that, the concentration and volume of the enema is modified, by trial and error. By the end of the week, about $95 \%$ of the patients are completely clean in the underwear and very happy [47].

During the first day of the program, the parents hear a lecture that discusses the general principles of the bowel management program. It is not unusual for us to perceive a degree of disappointment when the parents learn that mostly what we are offering is enemas. Most of the patients who we treat, already tried enemas and were unsuccessful. We have to explain to them that the difference this time is that these enemas are going to be used with a specific rationale that consists in first classifying the type of patient and the characteristic of his/her colon. Then, the enema will be tailored each day according to the family reports and the radiological image.

Another important feature of our program is that we review the entire clinical history and perform a series of tests with a specific purpose to determine the type of malformation that the patient was born with and the potential for bowel control that the patient has. This serves a very important purpose which is to detect a group of patients who were born with a good malformation, had a good surgical repair, suffer from severe constipation that was never treated correctly, and as a consequence, they have what we call overflow pseudoincontinence. In other words, these group of patients are not really incontinent and all what they need is to determine the amount of laxative that will empty their colon effectively, which usually is higher that what they previously received and is $2,3,4,5$ or 10 times more than what the books recommend. By properly treating the constipation, these patients stop having overflow pseudoincontinence and remain clean. 
Another advantage of determining the patient's original functional prognosis is to decide whether the bowel management will be indicated on long-term or permanent basis (like in cases born with malformations with poor prognosis) or, will be used on temporary basis, as in patients born with malformations with potential for bowel control. In addition, we consider it extremely important to adjust the parents expectations related to the future of the child. It is rather painful to meet parents that have been struggling, going from institution to institution with the hope of "curing" their child of fecal incontinence, only to find out that they were never told that the child was born with absent sacrum, tethered cord, absent sphincters and, therefore, will never be "normal" in terms of bowel control.

The experience accumulated in our center during 30 years includes the bowel management of at least 700 patients (Table 1). Most of the patients who we take care of in our bowel management clinic are patients operated on at other institutions.

Creating bowel management centers in different children's hospitals around the world is a necessity, since bowel management, when used and applied in an adequate way, allows greater improvement in the quality of life of children than any surgical procedure that we try for the management of fecal incontinence.

There is a certain degree of reluctance by parents to accept the bowel management program as a treatment for fecal incontinence. This is based on the several misconceptions. Some parents believe that enemas may produce malnutrition in their children due to the washing out of nutrients from the bowel. It is our job to explain to them that enemas only remove the waste material from the colon. Some parents believe that once you start a patient on enemas, they must be continued for life. This is partially true. If the patient was born with a very poor prognosis type of malformation, then most likely it is true that they will need enemas for life. On the other hand, if the patient was born with an anorectal malformation with potential for bowel control, then the bowel management is used on temporary basis, and every 6 months or every year, when the patient is on vacation, we try to stop the use of enemas

Table 1 Number of patients treated with our bowel management program and percentage of success in each group

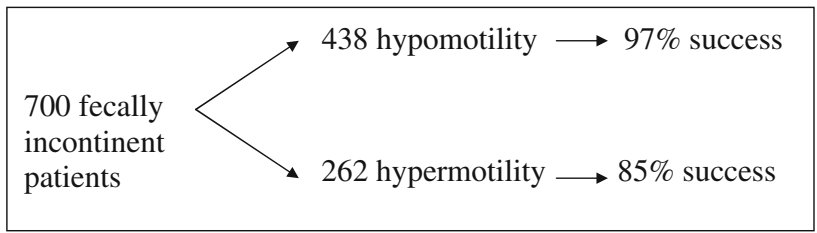

and see if the patient is manageable with other kinds of treatment including diet, oral medication and pectin. This is what we call "laxative trial". Another misconception is the idea that frequent administration of enemas will make a male patient homosexual, which, of course, is totally wrong. Finally, some parents believe that subjecting their child to a bowel management program may interfere with the natural toilet training process. This is also false. In fact, we are convinced that the bowel management may help the patient become toilet trained. A temporary bowel management in a patient, who has borderline bowel control, meaning a patient who has some elements for bowel control, will actually help the patient to become toilet trained, mainly because he or she learns the pleasurable feeling of being fresh and clean. In addition, every year the patient may become more cooperative and receptive to a regimen aimed at toilet training.

Once we are successful with the implementation of the bowel management regimen, and not before; in those patients that we believe will require the bowel management on long-term basis or perhaps for life, we offer the family an operation called a continent appendicostomy (Malone procedure) [84]. Some people call this the ACE procedure (antegrade continent enema). There are many techniques and different ways to do it [85-88]. There is no question that these antegrade enema procedures are beneficial and contribute to improve the quality of life of many patients. However, we firmly believe that these procedures are only indicated when the surgeon has demonstrated that the bowel management is successful. In other words, we are aware of the fact that many patients are being subjected to this kind of operation without having tried bowel management before. As a consequence, we receive many patients in our clinic with a Malone-ACE or button cecostomy type of procedure already done at another institution and they are still suffering the negative effects of fecal incontinence by passing stool in their underwear. In other words, they were subjected to an operation that did not benefit them. There is no demonstration that an enema administered from above (through the umbilicus and the appendix), works better than an enema given from below through the rectum [89]. The key is the enema, not its route of administration.

The goal of the bowel management program is to keep patients completely clean $24 \mathrm{~h}$ per day, so the patient can be socially accepted, attend school, play and become psychologically adjusted to society. Prior to the implementation of the bowel management program, all our patients are clinically studied, including the review of the medical records from previous operations and they all have a kidney ultrasound, voiding cystoureterogram, $\mathrm{X}$-ray study of the lumbar spine, X-ray study of the sacrum AP and lateral, contrast enema done with water-soluble material and an 
MRI of the spine to rule out the presence of tethered cord. With these studies, we are able to detect associated problems (mainly urologic and spinal) that sometimes the parents were not aware of and treat them adequately. In addition, as we mentioned, we try to determine the original malformation of the patient, and thus predict their prognosis.

The contrast enema is the most valuable of all studies, when planning a bowel management program. We administer water-soluble contrast without bowel preparation. This study allows us to classify the fecally incontinent patients into two main groups.

A. Patients that have a very large colon and, therefore, suffer from a tendency to have constipation and hypomotility (Fig. 1).

B. Patients who have either a short, spastic, non-dilated colon; or they have had a resection of colon for different reasons, and they suffer from a tendency to have diarrhea and hypermotility (Fig. 2).

This differentiation is crucial to have success in the bowel management.

When dealing with patients with Hirschsprung's disease who were operated on in the past and suffer from fecal incontinence, our evaluation includes an examination under anesthesia to determine the integrity or degree of damage of the anal canal and sphincters as a way to predict the future prognosis. Unfortunately, we have found a significant number of cases that had an operation for Hirschsprung's disease; come to us suffering from fecal incontinence and we have found that the anal canal was destroyed during the operation [49] (Fig. 3). If the anal canal is intact, then we recognize that the patient may have a better chance to recover bowel control with our assistance, but without the use of enemas. On the other hand, if the patient has a completely destroyed anal canal, most likely the bowel management with a daily enema will have to be implemented for life.

Interestingly, patients with spina bifida have a very characteristic type of colon that usually is not dilated, but rather redundant and yet, they suffer from fecal incontinence and severe hypomotility (Fig. 4). In the general population, as well as in cases with anorectal malformation, a dilated colon usually is associated with hypomotility and vice versa hypomotility usually is associated with a dilated colon. The exception seems to be the patients with spina bifida.

The first day of the week of bowel management, all the parents attend the conference given by one of the surgeons and followed by another conference given by one of our nurses, an expert in bowel management and in teaching the technique of enema administration. Then, each patient with their parents, individually meet with the responsible
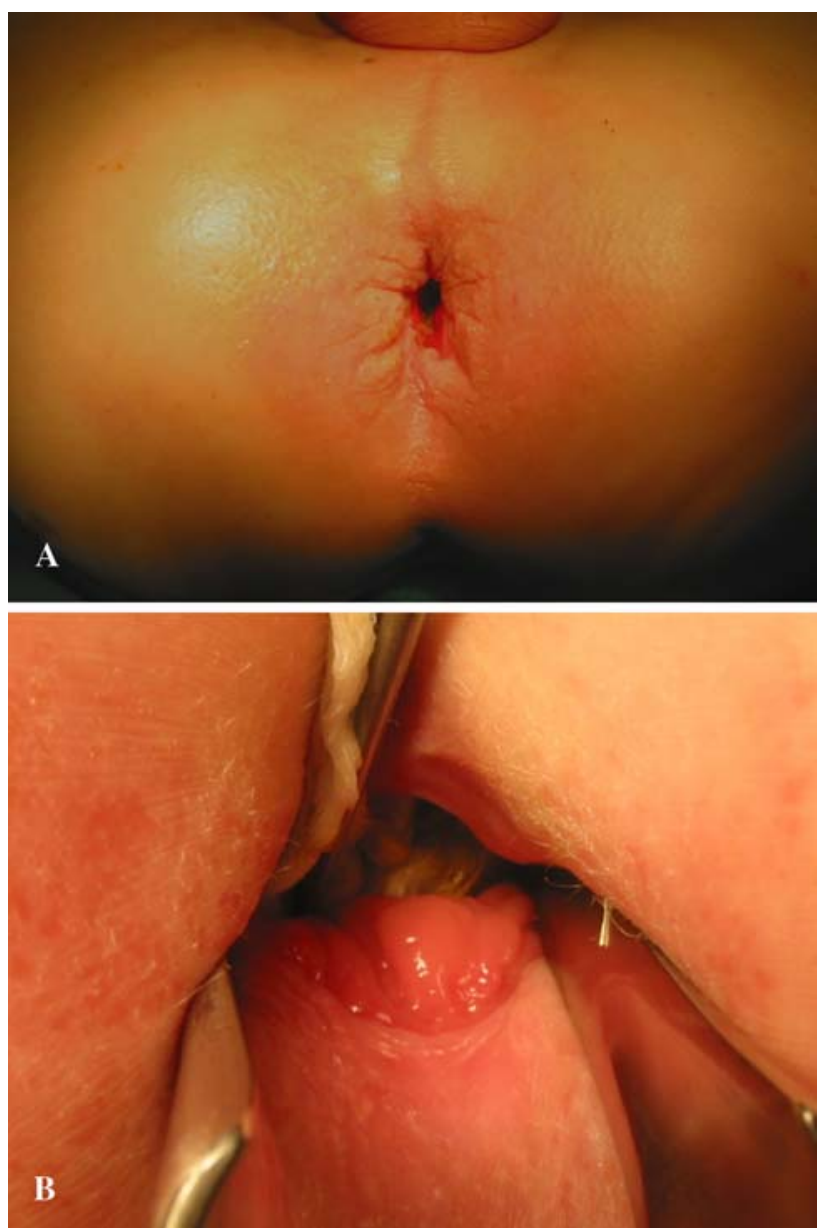

Fig. 3 Destroyed anal canal after a Hirschsprung's disease operation. a External appearance (patulous anus). b Anal examination shows colonic mucosa anastomosed to skin (no pectinate line)

surgeon to discuss the specific management of their child. Based on the characteristics of the contrast enema, the surgeon makes a first guess about the volume and content of the enema that the patient needs to clean his/her colon. Because the authors have been gaining a lot of experience in the bowel management that guess is usually a close estimate of the final enema. However, frequently the ingredients or volume have to be readjusted depending on the patient's response. All patients are managed on an ambulatory basis without admission to the hospital. Most of the patients come from other States and cities, and therefore, they stay in a nearby hotel or at the Ronald McDonald's house. The first day of the bowel management is on a Friday, so the patients will receive the enema prescribed on Saturday and Sunday. On Monday morning, the patients have an abdominal X-ray film; the parents call our nurses by phone and report what were the results of the enema. They are supposed to report not only whether or not the patient has been clean in the underwear for $24 \mathrm{~h}$, but also any problems experienced by the patient, such as pain 


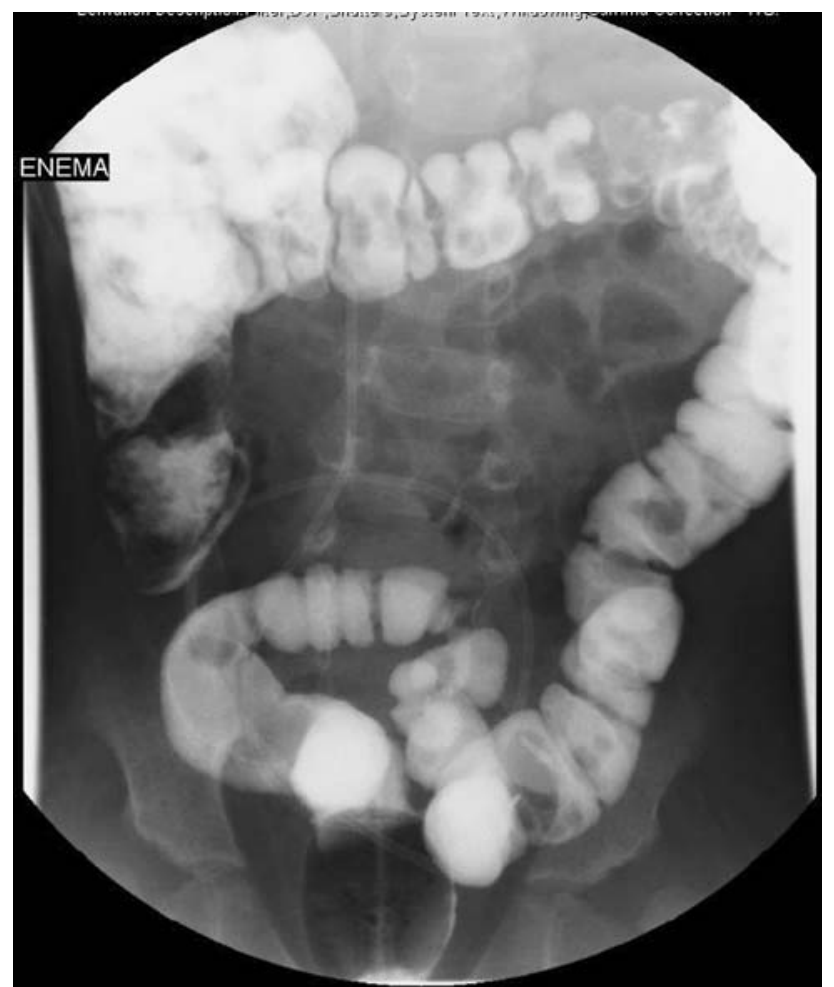

Fig. 4 Redundant non-dilated colon of patients with spina bifida

during the enema administration, leakage of the enema fluid and other symptoms such as nausea, vomiting, pallor and lethargy after the enema administration. In the case of a patient that has not been clean in the underwear, the nurse inquires about the amount, characteristic (solid or liquid) and time of the passing of stool in the underwear, an event that is known in our clinic as "accident".

In our literature review, we were unable to find authors that define the volume and content of an enema based on the characteristics of the patient's colon. We insist that this is the most important part and key for success.

Most of the patients born with ARM belong to the group of constipated and enlarged type of colon. However, some patients were subjected to different types of colonic resection for a variety of reasons. The most common reason was that the original colostomy was created too distal in the colon and when the surgeon was trying to repair the malformation they decided to resect the distal rectum and pull the colostomy down. Other times, the patients suffered from complications, such as intestinal obstruction and were subjected to resections of the colon. These patients tend to have loose stool as they have no rectal reservoir. Most patients operated on for ARM, without colonic resections, will suffer from constipation. In the group of fecally incontinent patients with megacolon and hypomotility (tendency to constipation), the key to success is to find the enema that has enough of a volume and concentration to be able to clean at least the entire left side of the colon every day and, therefore, keep the patient's underwear completely clean. Those patients do not need any specific medications or diet.

On the other hand, patients who suffer from either short or spastic colon and, therefore, hypermotility, with a tendency to diarrhea, usually need a small, non-concentrated type of enema because it is very easy to clean their colon. The difficult part, and the real challenge is in learning to manipulate the colonic motility, more specifically, slowing down the colon to keep the patient clean in between enemas. This is achieved by the administration of constipating diet and/or medications such as loperamide and bulking agents such as pectin.

The small group of patients in whom the program has been unsuccessful $(5 \%)$ is mainly represented by patients with hypermotility (Table 1). We are very successful in cleaning their colon, but we are unsuccessful in slowing down their colon enough to keep them clean in between enemas. In these cases, we ask for help from gastroenterologists, to try to determine the cause of the hypermotility and tendency to diarrhea and treat these when possible.

We never prescribed enemas and laxatives to the same patient, which is something that does not make sense. The enemas clean the colon, but then the laxative will promote the colonic motility, which will make the patient pass stool in between enemas, which of course is counter productive. The purpose of the bowel management is to clean the colon and to take advantage of the fact that the colon usually moves slowly and during the time in which the stool travels from the right colon to the left colon to keep the patient completely clean in the underwear. It is expected that by the time the new stool reaches the rectosigmoid, a new enema will be administered keeping the patient's underwear completely clean.

When the initial evaluation shows us that the patient was born with what we call a bad functional prognosis-type of malformation (bad sacrum, hemivertebra, tethered cord, bladder neck fistula, long common channel cloacas and ARM associated with spina bifida), we tell the parents that most likely the patient will need the bowel management on a long-term basis, perhaps for life.

When the patients are born in the middle of the spectrum of ARM, we recognize that the patient has some potential for bowel control, but we cannot guarantee if eventually the patient will be able to stop the enemas and to be managed just by diet and medication. For that we use a "laxative trial" whereby every 6 months or every year, those patients are encouraged to come back to our clinic to try to stop the use of enemas and see how much bowel control they have. Every year, we deal with an older patient and, therefore, hopefully, more cooperative and more interested in stopping the enemas. 
The laxative trial consists in providing the patient with a regime to try to condition his/her colon to empty at a predictable time. In addition, we try to determine the amount of laxative that will allow the patient to empty the colon trying to avoid liquid stool. We try to achieve all this by suggesting that the parents give three meals per day, try to maintain a regular type of diet, avoid snacks, administer the laxative in a single dose per day and give pectin by mouth to make the stool bulky. We monitor the amount of stool in the colon radiologically to be sure that the patient is not accumulating stool. Over a period of 1 week, we and the parents will have a very good idea as to the degree of bowel control that the patient has and whether or not that degree of bowel control is enough for the child to attend school and avoid embarrassing accidents. If the answer is no after a week, then the bowel management with enemas is re-initiated and a year later, the laxative trial is attempted again.

When the patients are born with a good prognosis type of malformation (perineal fistula, rectovestibular fistula, imperforate anus with no fistula and rectourethral bulbar fistula), all of these with a good sacrum, a normal spine, and have megacolon and tendency to constipation, the first thing we try to rule out is the condition known as overflow pseudoincontinence. If this is the case, we first disimpact the patient with three enemas (one containing saline solution and phosphate, the second saline solution and glycerin and the third with pure saline solution), we repeat these enemas for 3 days until we have a clean colon as demonstrated by an abdominal radiograph. After that we determine the amount of laxative needed daily to empty the patient's colon. To achieve this, we increase the amount of laxative (usually a senna derivative) on a daily basis, taking daily abdominal films, until we find the dosage that provokes a complete emptying of the colon as radiologically demonstrated. We try to avoid diarrhea and prescribe the use of pectin by mouth. This gives the stool a little bulk and makes the laxative more efficient. Once we reach the desired amount, if the patient is continent, we confirm the diagnosis of overflow pseudoincontinence. Determining the right amount of laxative makes the soiling disappears. It must be emphasized that these patients need a true stimulant laxative, not a stool softener. We then instruct parents and patients about the importance of continuing the laxative treatment on a daily basis to avoid the impaction and overflow pseudoincontinence. If we realize that the patient has been dirty for a long time and is not willing to cooperate with a laxative trial initially, we will treat the patient with enemas like all patients with fecal incontinence, in order for them to learn how it feels to be clean; but we recognize that the patient may actually have bowel control, and that this bowel management is temporary. When such patients with potential for bowel control have achieved a successful bowel management, they then come back with the intention of stopping the enemas, and are subjected to the "laxative trial".

Many parents express their concern about the fact that their previous experience with enemas was bad. In other words, the child believes that enemas hurt. We believe that when the enema is administered correctly, it should be totally painless. Sometimes, the "painful experience" derives from the fact that he/she suffers from severe chronic diaper rash equivalent to a second-degree burn of their buttocks. Therefore, they do not want anybody to get near that area and if somebody tries to give an enema, they frequently touch the irritated area and that is why they feel that an enema is painful. It takes a certain amount of time and explanation to convince the patient that there is no sensation inside the rectum and if we are careful and if he/ she does not move, the tube can go into the colon without touching sensitive areas. Another source of pain could be an enema that is administered very fast, which may produce abdominal cramps. For that, we recommend that the parents give an enema over the period of about $10 \mathrm{~min}$ and/ or warm the enema fluid up to body temperature.

\section{Contents of the enema}

The enema that we use in our clinic may contain one or several of the following components:

- normal saline solution;

- glycerin;

- soap;

- phosphate $\left(\right.$ Fleet $\left.^{\circledR}\right)$.

Occasionally, we may use other components such as GoLYTELY $^{\circledR}$. Early in the author's experience, the parents were encouraged to prepare their own saline solution mixing salt from the kitchen with tap water. We usually recommend $1 \mathrm{~L}$ of water to 1.5 teaspoons of salt. Many parents did this and some are still doing it very successfully. The majority of parents are extremely meticulous in the way they prepare the solution. However, we were really frightened when two patients came to the emergency room comatose and when they were studied, we found that the serum osmolality and concentration of sodium were extremely elevated. Retrospectively, we found that the parents were careless in preparing that solution. Because of that, we consider it safer to use normal saline solution from the pharmacy, which of course has the inconvenience of being more expensive. The volume of saline solution depends on the size of the colon, as estimated by the contrast enema, but usually varies from $250 \mathrm{~mL}$ to $1 \mathrm{~L}$.

Glycerin is added to the saline solution when considered necessary. Usually, we use approximately $20 \mathrm{~mL}$ of 
glycerin for every $500 \mathrm{~mL}$ of saline solution. The enema that we prescribe has different amounts of glycerin that varies from 5 to $30 \mathrm{~mL}$.

For soap, we use a form commercially known as Castile Soap ${ }^{\circledR}$ and we use one package $(9 \mathrm{~mL})$ for every $500 \mathrm{~mL}$ of saline solution. Occasionally, we use two or three packages.

The phosphate is added in a commercial form known as Fleet Enema $^{\circledR}$, which has different names in different countries. The pediatric formulation has $60 \mathrm{~mL}$ of monobasic sodium phosphate, $19 \mathrm{~g}$, and dibasic sodium phosphate, $7 \mathrm{~g}$. The adult formulation includes $120 \mathrm{~mL}$ of the same type of solution. We use a pediatric Fleet in patients up to 10 years of age. We usually mix this Fleet Enema with the saline solution. After the age of 10, we prescribe an adult Fleet $(120 \mathrm{~mL}$ of Fleet Enema). We never prescribe more than 1 Fleet Enema per day. Giving more than 1 Fleet enema per day exposes the patient to suffer from a crisis of hyperphosphatemia, hypocalcemia and tetany [90103]. Patients with underlying renal insufficiency must also avoid phosphate enemas.

We try to be as conservative as possible in the use of these different solutions. This means that if we can manage a patient with plain normal saline solution and keep him or her completely clean, that is all we use. However, many patients receiving only a saline enema do not respond; in other words, 2 or $3 \mathrm{~h}$ go by after the administration of the enema and nothing comes out through the anus, which indicates that the enema is not concentrated enough. In that case, the next option is to add glycerin that frequently makes the patient respond. Some patients do not respond to the administration of saline with glycerin or they respond only partially, in other words the colon does not empty completely. The X-ray film of the abdomen shows that the colon still has a significant amount of stool, and under those circumstances, we add soap to the enema solution. We leave the phosphate as a last resort, trying to avoid it as much as possible. Unfortunately, we have seen a number of patients who received phosphate enemas for a long period of time and they suddenly started behaving like patients with tendency to diarrhea; even when they originally suffered from constipation. A contrast enema in those patients shows a rather spastic, narrow and hyperactive left colon (Fig. 5). A colonoscopy showed signs of nonspecific colitis due to the chronic irritation produced by the phosphate solution. The patient may have signs or symptoms of severe colitis including the presence of blood and mucus in stool. In such cases, the administration of phosphate is immediately suspended. It takes several weeks or sometimes months for the symptoms to disappear.

To be successful with the bowel management, we believe that it is extremely important to give the parents enough information to be sure that they know how to

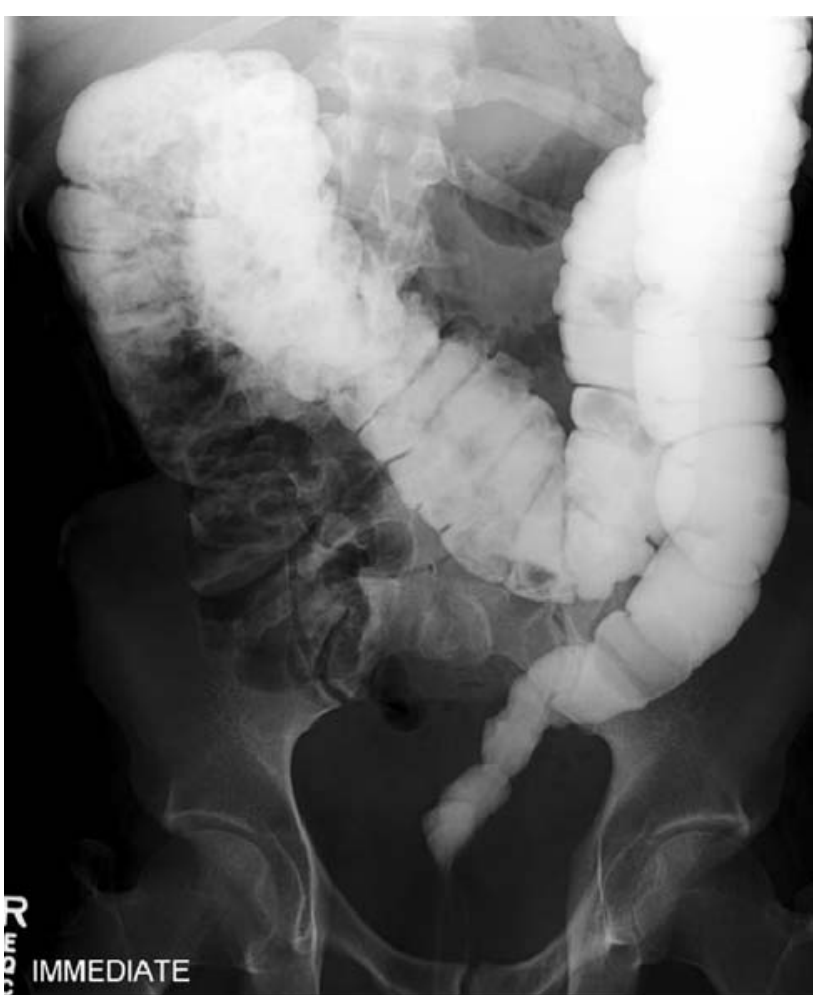

Fig. 5 Contrast enema showing a spastic rectosigmoid, after prolonged use of a phosphate-based enema

administer an enema. Prescribing an enema and assuming that the parents know what it is and know how to do it, frequently ends in a failure of the bowel management. It is not unusual to find parents that think that they are administering an enema and actually the fluid is leaking out of the patient. Obviously, they did not give an enema. When it is still questionable whether or not the parents know how to give an enema, "hands on" type of teaching is recommended. In other words, the patient and the parents are taken to a special room with appropriate facilities to administer an enema and there, the nurse demonstrates or supervises the procedure.

The position of the patient for the administration of an enema varies depending on the age (Fig. 6), since the enema must always be given taking advantage of gravity. Because most of the patients with fecal incontinence have poor sphincters, it is not unusual to see that when the parents try to give an enema, the fluid leaks out through an anus with a hypotonic sphincter. For that specific type of problem, we instruct the parents to introduce a \#20 or \#22 rubber tube as high as possible in the colon and then try again (Fig. 7). If this does not stop the problem of leakage of the fluid, then we recommend the use of a Foley balloon type of catheter. The balloon is inflated with different volumes depending on the size of the patient and the parents are supposed to apply traction on 
Fig. 6 Child's position to receive an enema according to their ages. Reprinted from Peña A, Levitt MA (2005) Pediatric surgical problems. In: Corman ML (ed) Colon and rectal surgery with kind permission from Lippincott Williams and Wilkins
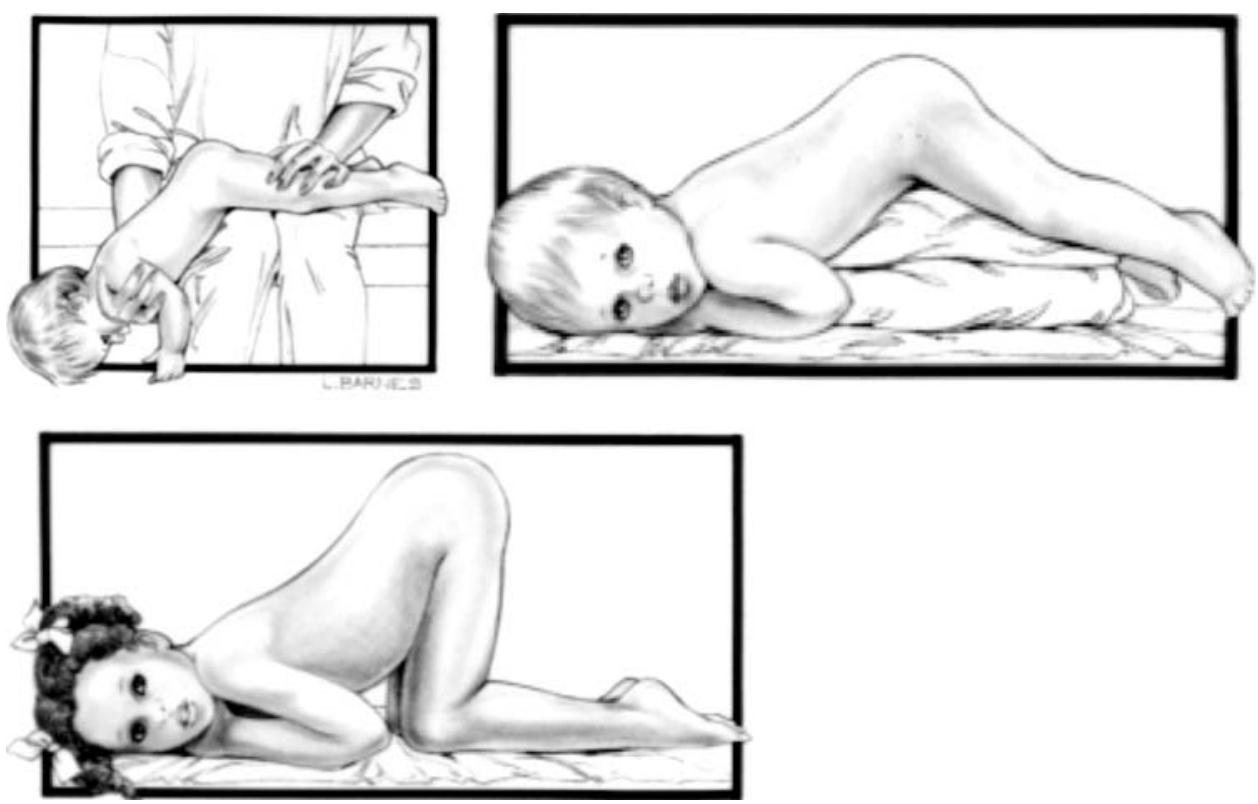

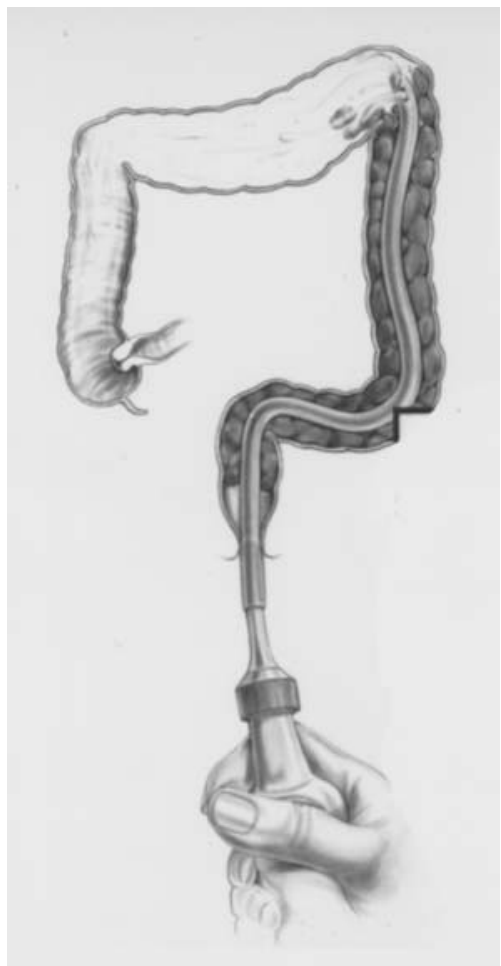

Fig. 7 Enema technique showing the tube high in the left colon

the catheter during the administration of the enema, to be sure that it does not leak (Fig. 8). The catheter is introduced, the balloon is inflated with $10 \mathrm{~mL}$ and then the mother or father must pull on the catheter in order for the balloon to act as a plug to prevent leakage. Every patient has a different caliber anus and a different-sized rectum; therefore, a different size balloon is needed for each

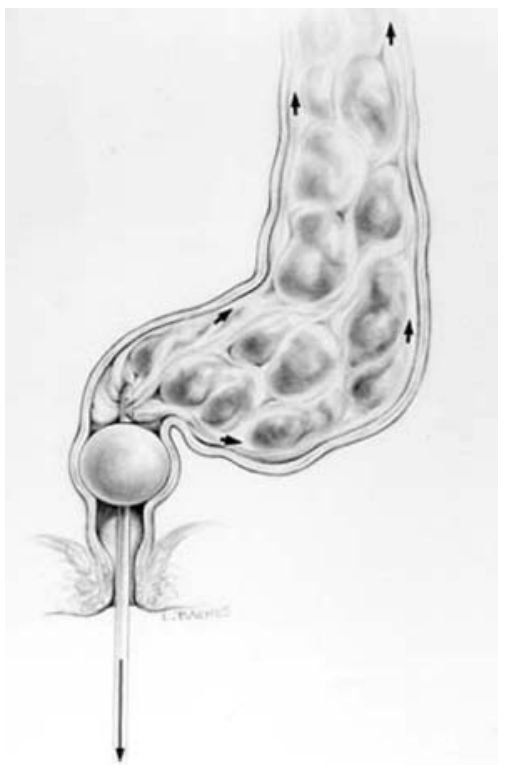

Fig. 8 Enema technique showing the Foley balloon inflated. Reprinted with kind permission from Ref. [38]

patient. We start by testing with a $10 \mathrm{~mL}$ balloon. If the balloon comes out through the anus, this means that the patient needs a larger balloon. Then, they repeat the maneuver inflating the balloon up to $20 \mathrm{~mL}$; if it comes out, they must try again inflating the balloon to $30 \mathrm{~mL}$. The patients who are most prone to leak during the administration of the enema are patients suffering from myelomeningocele. The patient with ARM respond better because they have a certain degree of fibrosis in the anal verge that usually allows them to hold the balloon inside during the administration of the enema. 


\section{Rationale to determine the volume and content of the enema}

If, in the course of the week of bowel management, we see an abdominal radiograph that shows a significant amount of stool in the colon (Fig. 9) and the patient is still passing stool in the underwear, that means that the enema used is not cleaning the colon enough and, therefore, we have to increase the volume or concentration of the enema. On the other hand, if the parents say that it took a long time for the patient to pass stool after the administration of an enema that means that the solution is not irritating enough to provoke the colonic peristalsis to empty the colon, in that case we must increase the concentration of the enema. In other words, increasing the concentration of the enema will shorten the time that passes between the administration of the enema and the emptying of the colon. We typically start by increasing the concentration of glycerin that is added to the volume of saline. Some patients have a negative reaction to glycerin such as severe cramps and nausea, in such cases we try soap. In some patients, we go as high as $30 \mathrm{~mL}$ of glycerin and the patient still does not respond, meaning that it takes a long time for him/her to pass stool or to empty, then we add soap in addition to the glycerin.

If the nurses give us information provided by the parents, indicating that the child reacted with vagal type of symptoms such as nausea, vomiting, or pallor, we try to

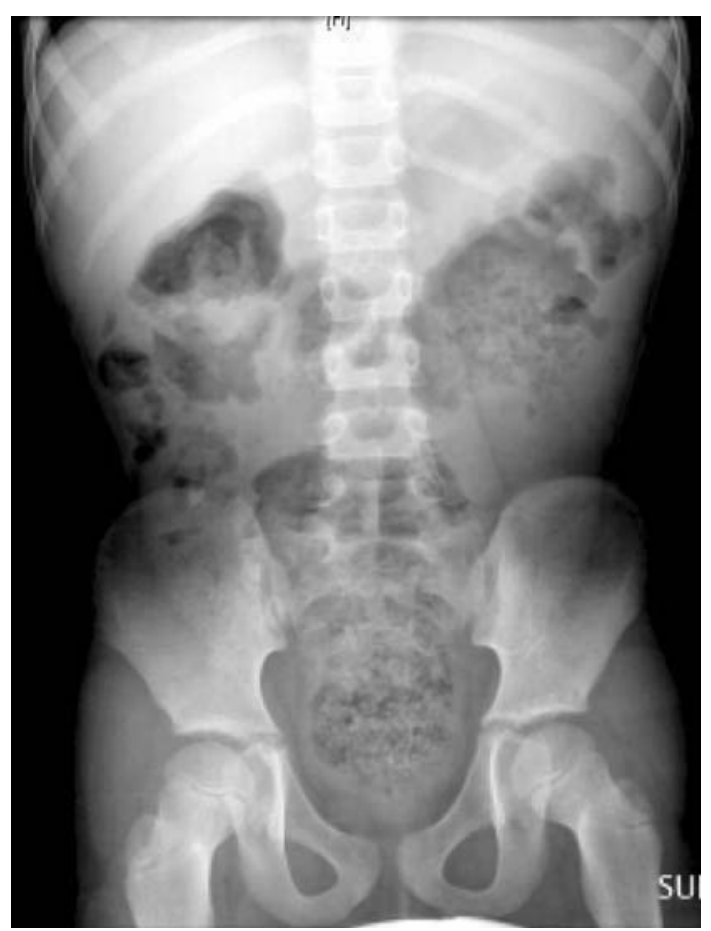

Fig. 9 Abdominal radiograph showing stool in the rectum and descending colon reduce the volume of the enema or try to give it slowly and warm the solution prior to its administration.

In cases when the X-ray image shows a completely clean colon (Fig. 10) and the child still passes stool in the underwear it means that the colon is moving too fast and is pushing liquid stool in between enemas. In these cases, we eliminate all irritants from the enema and administer only saline solution. In addition, those patients are the ones that need extra medical treatment, besides, the enema, to try to slow down the colon to keep the child clean between enemas. Our regimen in those patients includes:

A. Constipating diet.

B. Loperamide (Imodium).

C. Pectin.

D. Eliminating the irritating factor when known (lactose intolerance, food allergy, phosphate enema, inflammatory bowel disease).

The constipating diet we use is a very strict one. We recognize that every patient has a different susceptibility or idiosyncrasy to different types of foods. Because we are limited by a 1-week program, we prescribe a diet that has proved to be extremely constipating in most people (Table 2). Once we are successful with that specific diet, we advise the parents to try to individualize it trying to find

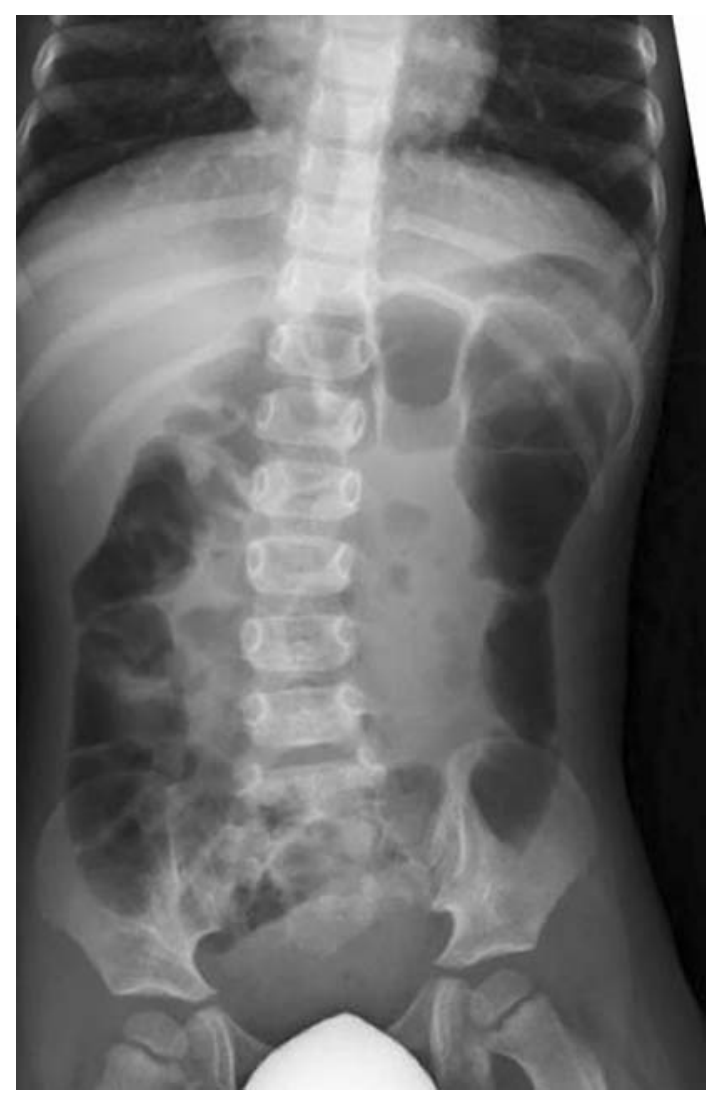

Fig. 10 Abdominal radiograph showing a completely clean colon 
Table 2 Constipating diet

\begin{tabular}{|c|c|}
\hline Food groups & Food recommended \\
\hline $\begin{array}{l}\text { Milk and milk } \\
\text { products }\end{array}$ & Plain rice milk \\
\hline Vegetables & None \\
\hline Fruits & Applesauce, apples without skin, bananas \\
\hline $\begin{array}{l}\text { Starches, bread and } \\
\text { grain }\end{array}$ & $\begin{array}{l}\text { Bread, crackers and cereals made from refined flours, pasta and noodles made from white flours, white rice, pretzels, } \\
\text { white potatoes without skin, dry cereals such as: Rice Crispies, Rice or Corn Chex, Corn Flakes, Kixx }\end{array}$ \\
\hline $\begin{array}{l}\text { Meat or meat } \\
\text { substitutes }\end{array}$ & $\begin{array}{l}\text { Baked, broiled, boiled or grilled meat, poultry or fish, lean deli meats such as ham and turkey and eggs (boiled, scrambled } \\
\text { or fried with allowed fats listed below) }\end{array}$ \\
\hline Fats and oils & $\begin{array}{l}\text { Limit amounts of butter, margarine and oils in food preparation during this phase, non-stick spray and non-fat butter } \\
\text { sprays are allowed }\end{array}$ \\
\hline Sweets and desserts & $\begin{array}{l}\text { Sugar free gelatin or popsicles, Rice Dream Frozen Dessert, sugar-free jelly and syrup, marshmallows, angel food cake } \\
\text { and vanilla wafers }\end{array}$ \\
\hline Beverages & Water, Gatorade, Propel, Sugar-Free Crystal Lite and Sugar-Free Kool-aid \\
\hline
\end{tabular}

out the real offending types of foods that produce loose stool. In other words, we know already that the patient remains completely clean with the very radical type of diet, but the patient obviously misses many types of food that he/she loves. We then allow the parents to introduce one specific type of food at a time over a period of 3 days. If the patient has no "accidents" (passing of stool in the underwear) that means that the specific type of food will now be allowed as part of the diet. Every 3 days, the parents will introduce a different type of food. The parents may find out that some specific foods produce diarrhea and that is an offender that should be avoided permanently.

The loperamide is administered at a maximum dosage, and once we see that the patient is completely clean, we can try to gradually decrease the amount of it, looking for the minimal dosage of medication capable of keeping the patient clean.

We like to say that fecal incontinence is not a psychological problem, but rather a physiologic one. Many of our patients have already seen psychiatrists and psychologists before coming to our clinic. Obviously, many patients suffering from fecal incontinence have secondary psychological problems. Yet, we firmly believe that most of the time those problems disappear when the patient is clean in the underwear.

The last visit to our clinic (the last day of the week), we explain to the parents that a successful bowel management is something adjustable. Sometimes, the same enema continues being successful for 1, 2, 3, 4 or even 10 years and no changes have to be introduced. Other times, a month after we implemented the bowel management, we get a phone call from the parents indicating that the patient is having "accidents' again. If that is the case, we ask them to take an abdominal radiograph of the abdomen and suggest to the parents to e-mail that to us. Based on the image, we can adjust the bowel management. In other words, if the patient's abdominal radiograph shows a lot of stool in the colon, that means it is time for the patient to receive either a larger volume type of enema, to increase the concentration of the different components of the enema or both. On the other hand, if we see that the patient has a completely clean colon that means that the enema is cleaning the colon very well, but the colon is moving too fast due to excessive irritation, ingestion of laxative foods or a virus. The management in that case is to insist on the constipating diet, to be sure that the patient is taking loperamide, and to increase the amount of pectin.

Lately, we have also been implementing our bowel management for the treatment of severe diaper rash in babies; mainly in patients with ARM after the colostomy is closed. During the 4 weeks after the colostomy is closed, if the patient has a severe diaper rash, we cannot administer large volume enemas, because of the fear of disrupting the colonic anastomosis at the colostomy closure site; we, therefore, suggest that the parents give a baby glycerine micro enema (Baby Lax ${ }^{\circledR}$ ) (which is equivalent to $10 \mathrm{~mL}$ of glycerin each) every $12 \mathrm{~h}$. By doing that the parents provoke a larger bowel movement and that allows him to stay clean of stool in the underwear for a longer period of time, which will help to clear up the diaper rash. After 1 month of surgery, we can then implement a full bowel management. Usually, we start with an enema with $250 \mathrm{~mL}$ of saline solution. The parents really like this bowel management for the treatment of severe diaper rash and actually, we believe that this management will help the baby to become toilet trained at the appropriate age.

Another modality of bowel management is the use of enemas through the colostomy of a patient who comes to us with what supposedly was an end, "permanent" colostomy. Enemas through the colostomy have been used for many times in the past [104-108]. Yet, those were used for the convenience of the patient to avoid walking 
around with a bag full of stool particularly if the stool is liquid. This exposes the patient to "accidents of leakage of stool" when the bag, for instance, detaches from the abdominal wall. We have been using the enema through the stoma with a different purpose [109]. In patients who had a colostomy and the previous surgeons thought that it was a "colostomy for life", we offer the bowel management through the stoma with the specific purpose to try to eliminate the colostomy and have a pull through. In order for us to determine whether the patient is a good candidate for a pull through, particularly in patients who were born with cloacal exstrophy and have different degrees of a short colon, we implement the bowel management through the stoma. These patients usually need loperamide and a constipating diet, in addition to the enemas through the stoma. If we are successful with the bowel management, meaning that the patient spends $24 \mathrm{~h}$ passing absolutely no stool into the bag, that means that the patient is a potential candidate to undergo a pull through of the colostomy down to the perineum. The bowel management gives the patient and the family an idea of the effort that the patient has to make to stay clean. Passing of stool into the stoma bag will represent leakage of stool in the underwear in the event of the pull through. The patient takes a few weeks or months to think about how his life is going to be in the event of a pull through of the colostomy. Many patients like the idea and are subjected to a pull through of the colostomy. An antegrade enema mechanism such as a Malone appendicostomy usually accompanies the pull through. Some patients are not convinced about the pull through, yet they like very much the enema through the colostomy because it allows them to walk around with a stoma bag completely empty which will allow them to practice sports and be physically very active without the risk of leakage.

\section{Conclusion}

It is currently possible to have $95 \%$ success rate with the administration of individually designed enema to a patient with fecal incontinence and monitoring the amount and distribution of stool in the colon after the administration of an enema and in addition manipulating colonic motility with diet and/or medication. The ideal regimen is a combination of different treatment modalities employed in a rational way, making sure that the patient has one bowel movement every day and stays clean between enemas.

Open Access This article is distributed under the terms of the Creative Commons Attribution Noncommercial License which permits any noncommercial use, distribution, and reproduction in any medium, provided the original author(s) and source are credited.

\section{References}

1. US census bureau http://www.census.gov/

2. CIA https://www.cia.gov

3. Shurtleff DB (2004) Epidemiology of neural tube defects and folic acid. Cerebrospinal Fluid Res 1:5

4. Peña A, Levitt MA (2005) Imperforate anus and cloacal malformations. In: Ashcraft KW, Holcomb GW, Murphy JP (eds) Pediatric surgery, 4th edn. W.B. Saunders, Philadelphia, pp 496-517

5. Lary JM, Edmonds LD (1996) Prevalence of spina bifida at birth-United States, 1983-1990: a comparison of two surveillance systems. MMWR CDC Surveill 45:15-26

6. Poley MJ, Stolk EA, Langemeijer RA et al (2000) Cost-effectiveness of treatment for congenital anorectal malformation. Annu Meet Int Soc Technol Assess Health Care Int Soc Technol Assess Health Care Meet 16:281

7. Bowman RM, McLone DG, Grant JA et al (2001) Spina bifida outcome: a 25-year prospective. Pediatr Neurosurg 34:114-120

8. Wong LYC, Paulozzi LJ (2001) Survival of infants with spina bifida: a population study, 1979-94. Pediatr Perinat Epidemiol $15: 374-378$

9. Read M, Read NW, Barber DC et al (1982) Effects of loperamide on anal sphincter function in patients complaining of chronic diarrhea with fecal incontinence and urgency. Dig Dis Sci 27:807-814

10. Yoshioka K, Keighley MRB (1988) Clinical and manometric assessment of gracilis muscle transplant for fecal incontinence. Dis Colon Rectum 31:767-769

11. Jorge JMN, Wexner SD (1993) Etiology and management of fecal incontinence. Dis Colon Rectum 36:77-97

12. Longo EL, Vernava AM III (1993) Prokinetic agents for lower gastrointestinal motility disorders. Dis Colon Rectum 36:696708

13. Heikenen JB, Werlin SL, Di Lorenzo C et al (1999) Colonic motility in children with repaired imperforate anus. Dig Dis Sci 44:1288-1292

14. Doughty D (1996) A physiologic approach to bowel training. J WOCN 23:46-56

15. Briel JW, Shouten WR, Vlot EA et al (1997) Clinical value of colonic irrigation in patients with continence disturbances. Dis Colon Rectum 40:802-805

16. Jensen L (1997) Fecal incontinence: evaluation and treatment. J WOCN 24:277-282

17. Soffer EE, Hull T (2000) Fecal incontinence: a practical approach to evaluation and treatment. Am J Gastroenterol 95:1873-1880

18. Varma MG, Madoff RD (2001) Fecal incontinence. Clin Colon Rectal Surg 14:253-263

19. Bouchoucha M, Devroede G, Faye A et al (2002) Importance of colonic transit evaluation in the management of fecal incontinence. Int J Colorectal Dis 17:412-417

20. Norton C, Chelvanayagam S, Wilson-Barnett J et al (2003) Randomized controlled trial of biofeedback for fecal incontinence. Gastroenterology 125:1320-1329

21. Christensen P, Olsen N, Krogh K et al (2003) Scintigraphic assessment of retrograde colonic washout in fecal incontinence and constipation. Dis Colon Rectum 46:68-76

22. Margolin DA (2003) New options for the treatment of fecal incontinence. Clin Colon Rectal Surg 16:173-179

23. Koch SM, Uludag O, Rongen MJ et al (2004) Dynamic graciloplasty in patients born with an anorectal malformation. Dis Colon Rectum 47:1711-1719

24. Casal E, Ildefonso AS, Carracedo R et al (2004) Artificial bowel sphincter in severe anal incontinence. Colorectal Dis 6:180-184 
25. Gosselink MP, Darby M, Zimmerman DDE et al (2005) Longterm follow-up of retrograde colonic irrigation for defaecation disturbances. Colorectal Dis 7:65-69

26. Norton C, Burch J, Kamm MA (2005) Patient's views of a colostomy for fecal incontinence. Dis Colon Rectum 48:10621069

27. Halverson AL (2005) Nonoperative management of fecal incontinence. Clin Colon Rectal Surg 18:18-21

28. Papaconstantinou HT (2005) Evaluation of anal incontinence: minimal approach, maximal effectiveness. Clin Colon Rectal Surg 18:9-16

29. Dobben AC, Terra MP, Berghmans B et al (2006) Functional changes after physiotherapy in fecal incontinence. Int J Colorectal Dis 21:515-521

30. Ehrempreis ED, Chang D, Eichenwald E (2006) Pharmacotherapy for fecal incontinence: a review. Dis Colon Rectum 50:641-649

31. Tan JJY, Chan M, Tjandra JJ (2007) Evolving therapy for fecal incontinence. Dis Colon Rectum 50:1950-1967

32. Tracy H (2007) Fecal incontinence. Clin Colon Rectal Surg 20:118-124

33. Lauti M, Scott D, Thompson-Fawcett MW (2007) Fibre supplementation in addition to loperamide for faecal incontinence in adults: a randomized trial. Colorectal Dis 10:553-562

34. Tjandra JJ, Chan MKY, Yeh CH (2008) Sacral nerve stimulation is more effective than optimal medical therapy for severe fecal incontinence: a randomized, controlled study. Dis Colon Rectum 51:494-502

35. Koch AM, Uludag O, Naggar KE et al (2008) Colonic irrigation for defecation disorders after dynamic graciloplasty. Int $\mathbf{J}$ Colorectal Dis 32:195-200

36. Bellicini N, Molloy PJ, Cushaj P et al (2008) Fecal incontinence: a review. Dig Dis Sci 53:41-46

37. Troche JMR, Ozturk R, Philips C et al (2008) Cholestyramine: a useful adjunct for the treatment of patients with fecal incontinence. Int J Colorectal Dis 32:189-194

38. Peña A, Guardino K, Tovilla JM et al (1998) Bowel management for fecal incontinence in patients with anorectal malformations. J Pediatr Surg 33:133-137

39. Van Ginkel R, Benninga MA, Blommaart PJE et al (2000) Lack of benefit of laxatives as adjunctive therapy for functional nonretentive fecal soiling in children. J Pediatr 137:808-813

40. Price K, Butler U (2001) Bowel and bladder management in children with disabilities. Curr Paediatr 11:143-148

41. Singh SJ, Cummins G, Manglick P et al (2002) How to test the safety of homemade antegrade colonic washout fluid? Pediatr Surg Int 18:81-82

42. Wagener S, Shankar KR, Turnock RR et al (2004) Colonic transit time: what is normal? J Pediatr Surg 39:166-169

43. Mattsson S, Gladh G (2006) Tap-water enema for children with myelomeningocel and neurogenic bowel dysfunction. Acta Paediatr 95:369-374

44. Winckel MV, Biervliet SV, Laecke EV et al (2006) Is anal plug useful in the treatment of fecal incontinence in children with spina bifida or anal atresia? J Urol 176:342-344

45. Shoshan L, Ben-Zvi D, Katz-Leurer M (2008) Use of anal plug in the treatment of fecal incontinence in patients with meningomyelocele. J Pediatr Nurs 23:395-399

46. Griffin SJ, Parkinson EJ, Malone PSJ (2008) Bowel management for paediatric patients with faecal incontinence. J Pediatr Urol 4:387-392

47. Bischoff A, Levitt MA, Bauer C et al (2009) Treatment of fecal incontinence with a comprehensive bowel management program. J Pediatr Surg 44:1278-1284

48. Levitt M, Peña A (2009) Update on paediatric faecal incontinence. Eur J Pediatr Surg 19:1-9
49. Levitt M, Martin C, Olesevich M, Bauer C, Jackson L, Peña A (2009) Hirschsprung's disease and fecal incontinence: diagnostic and management strategies. J Pediatr Surg 44:271-277

50. Wilmshurst JM, Kelly R (1999) Malgorzata B: presentation and outcome of sacral agenesis: 20 years' experience. Dev Med Child Neurol 41:806-812

51. Morera C, Nurko S (2003) Rectal manometry in patients with isolated sacral agenesis. J Pediatr Gastroenterol Nutr 37:47-52

52. Gabra HO, Jusudason EC, McDowel HP et al (2006) Sacrococcygeal teratoma: a 25 year experience in a UK regional center. J Pediatr Surg 41:1513-1516

53. Derikx JP, De Backer A, van de Schoot L et al (2007) Longterm functional sequelae of sacrococcygeal teratoma: a national study in the Netherlands. J Pediatr Surg 42:1122-1126

54. Tsai CJ, Leitzmann MF, Willett WC et al (2004) Long-term intake of dietary fiber and decreased risk of cholecystectomy in women. Am J Gastroenterol 99:1364-1370

55. Slavin JL (2008) Position of the American dietetic association: health implications of dietary fiber. J Am Diet Assoc 108:17161731

56. Rintala R, Lindahl H, Louhimo I (1988) Biofeedback conditioning for fecal incontinence in anorectal malformations. Pediatr Surg Int 3:418-421

57. Bharucha AE (2004) Outcome measures for fecal incontinence: anorectal structure and function. Gastroenterology 126(Suppl 1):S90-S98

58. Chew MH, Quah HM, Ooi BS et al (2007) A prospective study assessing anal plug for containing of faecal soilage and incontinence. Colorectal Dis 10:677-680

59. Pickrell KL, Georziade N, Crawford H et al (1952) Construction of a rectal sphincter and restoration of anal continence by transplanting the gracilis muscle. Ann Surg 135:853-862

60. Hakelius L (1975) Free autogenous muscle, transplantation in two cases of total anal incontinence. Acta Chir Scand 141:69-75

61. Puri P, Nixon HH (1976) Levatorplasty: a secondary operation for fecal incontinence following primary operation for anorectal agenesis. J Pediatr Surg 11:77-82

62. Brandesky G, Holschneider AM (1976) Operations for the improvement of fecal incontinence. Prog Pediatr Surg 9:105114

63. Raffensperger J (1979) The gracilis sling for fecal incontinence. J Pediatr Surg 14:794-797

64. Mollard P, Valla V, de Beaujeu MJ (1979) Incontinence anale apres imperforation: traitment per transplantation musculaire libre. Chir Pediatr 20:205-208

65. Peña A (1983) Posterior sagittal anorectoplasty as a secondary operation for the treatment of fecal incontinence. J Pediatr Surg 18:762-773

66. Skef Z, Radhakrishnan J, Reyes HM (1983) Anorectal continence following sphincter reconstruction utilizing the gluteus maximus muscle: a case report. J Pediatr Surg 18:779-781

67. Holschneider AM, Hecker WC (1984) Smooth muscle reverse plasty: a new method to treat anorectal incontinence in infants with high anal and rectal atresia-results after gracilis plasty and free muscle transplantation. Prog Pediatr Surg 17:131145

68. Holschneider AM, Amano S, Urban A et al (1985) Free and reverse smooth muscle plasty in rats and goats. Dis Colon Rectum 28:786-794

69. Kottmeier PK, Velcek FT, Klotz DH et al (1986) Results of levatorplasty for anal incontinence. J Pediatr Surg 24:647-650

70. Baeten CG, Konsten J, Heineman E et al (1994) Dynamic graciloplasty for anal atresia. J Pediatr Surg 29:922-925

71. Ninan GK, Puri P (1994) Levatorplasty using a posterior sagittal approach in secondary faecal incontinence. Pediatr Surg Int 9:17-20 
72. Silva GM, Jorge JMN, Belin B et al (2004) New surgical options for fecal incontinence in patients with imperforate anus. Dis Colon Rectum 47:204-209

73. Takahashi T, Garcia-Osogobio S, Valdovinos MA et al (2002) Radio-frequency energy delivery to the anal canal for the treatment of fecal incontinence. Dis Colon Rectum 45:915-922

74. Takahashi T, Garcia-Osogobio S, Valdovinos MA et al (2003) Extended two-year results of radio-frequency energy delivery for the treatment of fecal incontinence. Dis Colon Rectum 46:711-715

75. Parisien CJ, Corman ML (2005) The Secca procedure for the treatment of fecal incontinence: definitive therapy or short-term solution. Clin Colon Rectal Surg 18:42-45

76. Takahashi-Monroy T, Morales M, Garcia-Osogobio et al (2008) SECCA procedure for the treatment of fecal incontinence: results of five-year follow-up. Dis Colon Rectum 51:355-359

77. Uludag O, Koch SMP, Dejong CHC et al (2006) Sacral neuromodulation: does it affect colonic transit time in patients with faecal incontinence? Colorectal Dis 8:318-322

78. Gourcerol G, Gallas S, Michot F et al (2006) Sacral nerve stimulation in fecal incontinence: are there factors associated with success? Dis Colon Rectum 50:3-12

79. Mowatt G, Glazener C, Jarrett M (2008) Sacral nerve stimulation for fecal incontinence and constipation in adults: a short version Cochrane review. Neurol Urodyns 27:155-161

80. Humphreys MR, Vandersteen DR, Slezak JM et al (2006) Preliminary results of sacral neuromodulation in 23 children. J Urol 176:2227-2231

81. Crawshaw AP, Pigott L, Potter MA et al (2004) A retrospective evaluation of rectal irrigation in the treatment of disorders of faecal continence. Colorectal Dis 6:185-190

82. Schmelzer M, Schiller LR, Meyer R et al (2004) Safety and effectiveness of large volume enema solutions. Appl Nurs Res $17: 265-274$

83. Bani-Hani AH, Cain MP, King S et al (2008) Tap water irrigation and additives to optimize success with the Malone antegrade continence enema: The Indiana University Algorithm. J Urol 180:1757-1760

84. Malone PS, Ransley PG, Kiely EM (1990) Preliminary report: the antegrade continence enema. Lancet 336:1217-1218

85. Shandling B, Chait PG, Richards HF (1996) Percutaneous cecostomy: a new technique in the management of fecal incontinence. J Pediatr Surg 31:534-537

86. Levitt MA, Soffer SZ, Peña A (1997) Continent appendicostomy in the bowel management of fecal incontinent children. J Pediatr Surg 32(11):1630-1633

87. Monti PR, Carvalho JR, Arap S (2000) The Monti procedure: applications and complications. Urol 55:616-621

88. Duel BP, Gonzalez R (1999) The button cecostomy for management of fecal incontinence. Pediatr Surg Int 15:559-561

89. Matsuno D, Yamazaki Y, Suzuki M et al (2008) The role of retrograde colonic enema in children with spina bifida: is it inferior to the antegrade continence enema? J Urol 179:296

90. Davis RF, Eichner JM, Bleyer WA et al (1977) Hypocalcemia, hyperphosphatemia, and dehydration following a single hypertonic phosphate enema. J Pediatr 90:484-485
91. Sotos JF, Cutler EA, Finkel MA et al (1977) Hypocalcemic coma following two pediatric phosphate enemas. Pediatrics 60:305-307

92. McCabe M, Sibert JR, Routledge PA (1991) Phosphate enemas in childhood: a cause of concern. Br Med J 302:1074

93. Hunter MF, Ashton MR, Griffiths DM et al (1993) Hyperphosphataemia after enemas in childhood: prevention and treatment. Arch Dis Child 68:233-234

94. Craig JC, Hodson EM, Martin HC (1994) Phosphate enema poisoning in children. Med J Aust 160:347-351

95. Harrington L, Schuh S (1997) Complications of fleet enema administration and suggested guidelines for use in the pediatric emergency department. Pediatr Emerg Care 13:225-226

96. Helikson MA, Parham WA, Tobias JD (1997) Hypocalcemia and hyperphosphatemia after phosphate enema in a child. $\mathrm{J}$ Pediatr Surg 32:1244-1246

97. Soumoy MP, Bachy A (1998) Risk of phosphate enemas in the infant. Arch Pediatr 5:1221-1223

98. Ismail EA, Al-Mutairi G, Al-Anzy H (2000) A fatal small dose of phosphate enema in a young child with no renal or gastrointestinal abnormality. J Pediatr Gastroenterol Nutr 30:220-221

99. Walton DM, Thomas DC, Aly HZ et al (2000) Morbid hypocalcemia associated with phosphate enema in a six week old infant. Pediatrics 106:E37

100. Melvin JD, Watts RG (2002) Severe hypophosphatemia: a rare cause of intravascular hemolysis. Am J Hematol 69:223-224

101. Everman DB, Nitu ME, Jacobs BR (2003) Respiratory failure requiring extracorporeal membrane oxygenation after sodium phosphate enema intoxication. Eur J Pediatr 162:517-519

102. Marraffa JM, Hui A, Stork CM (2004) Severe hyperphosphatemia and hypocalcemia following the rectal administration of a phosphate-containing Fleet pediatric enema. Pediatr Emerg Care 20:453-456

103. Biebl A, Grillenberger A, Schmitt K (2009) Enema-induced severe hyperphosphatemia in children. Eur J Pediatr 168:111112

104. Dini D, Venturini M, Forno G et al (1991) Irrigation for colostomized cancer patients: a rational approach. Int J Colorect Dis 6:9-11

105. O'Bichere A, Sibbons P, Dore C et al (2000) Experimental study of faecal continence and colostomy irrigation. Br J Surg 87:902908

106. Karadag A, Mentes BB, Ayaz S (2005) Colostomy irrigation: results of 25 cases with particular reference to quality of life. Clin Proc 14:479-485

107. Cesaretti IUR, Santos VLCG, Schiftan SS et al (2008) Colostomy irrigation: a review of technical aspects. Acta Paul Enferm 21:338-344

108. Lizarondo L, Gyi AA, Schultz T (2008) Fluid regimens for colostomy irrigation: a systematic review. Int J Evid Based Health Care 6:303-310

109. Levitt ML, Mak GA, Falcone RA et al (2008) Cloacal exstrophy-pull through or permanent stoma? A review of 53 patients. J Pediatr Surg 43:164-170 